\section{Transcription switches for protoxylem and metaxylem vessel formation}

\author{
Minoru Kubo, ${ }^{1}$ Makiko Udagawa, ${ }^{1}$ \\ Nobuyuki Nishikubo, ${ }^{1}$ Gorou Horiguchi, ${ }^{1,5}$ \\ Masatoshi Yamaguchi, ${ }^{1}$ Jun Ito, ${ }^{2}$ \\ Tetsuro Mimura, ${ }^{3}$ Hiroo Fukuda, ${ }^{1,4}$ and \\ Taku Demura ${ }^{1,6}$
}

${ }^{1}$ RIKEN Plant Science Center, Yokohama, Kanagawa 230-0045, Japan; ${ }^{2}$ RIKEN Discovery Research Institute, Wako, Saitama 351-0198, Japan; ${ }^{3}$ Department of Biology, Faculty of Sciences, Kobe University, Kobe, Hyogo 657-8501, Japan;

${ }^{4}$ Department of Biological Sciences, Graduate School of Science, The University of Tokyo,

Bunkyo-ku, Tokyo 113-0033, Japan

Land plants evolved xylem vessels to conduct water and nutrients, and to support the plant. Microarray analysis with a newly established Arabidopsis in vitro xylem vessel element formation system and promoter analysis revealed the possible involvement of some plant-specific NAC-domain transcription factors in xylem formation. VASCULAR-RELATED NAC-DOMAIN6 (VND6) and $V N D 7$ can induce transdifferentiation of various cells into metaxylem- and protoxylem-like vessel elements, respectively, in Arabidopsis and poplar. A dominant repression of VND6 and VND7 specifically inhibits metaxylem and protoxylem vessel formation in roots, respectively. These findings suggest that these genes are transcription switches for plant metaxylem and protoxylem vessel formation.

Supplemental material is available at http://www.genesdev.org.

Received May 9, 2005; revised version accepted June 17, 2005.

Xylem vessels, a conductive component of the vascular tissues in plants, are found throughout the plant body. To colonize the land, plants have evolutionarily developed different types of xylem vessels that function in the long-distance transport of water, various nutrients, and signaling molecules throughout their life (Raven et al. 1999). Two types of vessels mature in characteristic positions within protoxylem and metaxylem of the primary xylem tissue that differentiates from the procambium during the early ontogeny of a plant. The protoxylem vessels, which commonly have annular and spiral thickenings, mature before the surrounding organs have elongated. These are frequently destroyed by the exten-

[Keywords: VASCULAR-RELATED NAC-DOMAIN; xylem vessel; vascular development; cell fate; transdifferentiation; Arabidopsis]

${ }^{5}$ Present address: National Institute for Basic Biology/Center for Integrative Bioscience, Okazaki, Aichi 444-8585, Japan.

${ }^{6}$ Corresponding author.

E-MAIL demura@riken.jp; FAX 81-45-503-9609.

Article and publication are at http://www.genesdev.org/cgi/doi/10.1101/ gad.1331305 sion of the surrounding tissues. The metaxylem vessels, which usually have reticulate and pitted thickenings, mature after the surrounding organs complete their growth. In contrast to protoxylem vessels, they are not destroyed, and constitute the water-conducting tubes of the mature plant (Esau 1977). In Arabidopsis roots, two protoxylem vessels are typically formed at the outermost position of the vascular system, between which three to four metaxylem vessels develop (Supplementary Fig. S1).

Recent forward genetic and molecular biological approaches have revealed several aspects of xylem formation that are affected by several key genes (Ye 2002; Fukuda 2004). These genes are related to auxin transport and signaling, and include PINFORMED1 (Gälweiler et al. 1998) and MONOPTEROS (Przemeck et al. 1996), the xylogen genes related to cell-cell interactions (Motose et al. 2004); genes related to brassinosteroid biosynthesis and signaling such as CPD (Mathur et al. 1998a), DWF4 (Choe et al. 1998), and BRLs (Caño-Delgado et al. 2004; Zhou et al. 2004); genes related to pattern formation such as the HD-ZIPIII family genes (Ohashi-Ito and Fukuda 2003); the KANADI gene family (Emery et al. 2003); and $A P L$, related to xylem-phloem switching (Bonke et al. 2003). However, the hierarchical genetic control of differentiation of individual xylem cells is still poorly understood. In this study, we identified VND6 and VND7, which belong to plant-specific transcription factors, NAC-domain proteins that can induce transdifferentiation of various types of cells into metaxylemand protoxylem-like vessel elements, respectively. It is suggested that VND6 and VND7 are transcription switches for plant metaxylem and protoxylem vessel formation, respectively.

\section{Results and Discussion}

We have uncovered an expression profile of 9000 genes during xylem vessel element differentiation in an in vitro Zinnia cell culture (Demura et al. 2002). To gain an expression profile of xylem cell-differentiation-related genes in Arabidopsis, we established an in vitro xylem vessel element inducible system from Arabidopsis suspension cells. In this system, $\sim 50 \%$ of subcultured cells of Arabidopsis ecotype Col-0 differentiate into xylem vessel elements within $7 \mathrm{~d}$ in the presence of $1 \mu \mathrm{M}$ brassinolide and $10 \mathrm{mM}$ boric acid (Fig. 1A,B). Microarray analysis with the Arabidopsis full-genome GeneChip array ATH1 (Affymetrix) indicated that 1705 genes showed more than an eightfold change in expression over the time course. These were clustered into 23 sets using the QT clustering method (Fig. 1C; Supplementary Table S1). Of these, genes in Set 3 (156 genes), Set 8 (58 genes), and Set 22 (10 genes) showed up-regulated expression just when the xylem vessel elements were actively forming (6 d after induction). They encoded a variety of proteins closely associated with particular morphogenetic events such as secondary cellwall formation (cellulose synthases, xylanases, and laccases) and programmed cell death (nucleases and proteases). A promoter analysis of three selected genesxylanase AtXyn3 (At4g08160) (Sawa et al. 2005), cellulose synthase IRX3 (At5g17420) (Taylor et al. 1999), and laccase (At2g38080) (Oh et al. 2003)-was conducted with the cyan or yellow fluorescence protein gene (CFP 



C
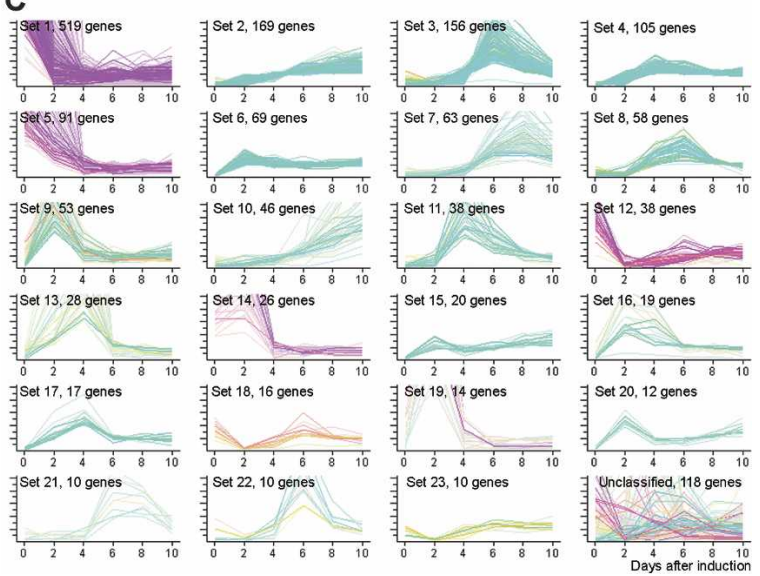

Figure 1. The Arabidopsis in vitro xylem vessel element formation system. (A) Xylem vessel elements induced in Arabidopsis suspension cells cultured for $7 \mathrm{~d}$. Bar, $50 \mu \mathrm{m}$. (B) Frequency of xylem vessel element formation. Results are means $\pm \operatorname{SD}(n=3)$. $(C)$ Hierarchical clustering of developmentally regulated genes during in vitro xylem vessel element formation. Colors indicate expression levels at $0 \mathrm{~d}$ after induction as follows: (magenta) high; (yellow) medium; (cyan) low.

or YFP, respectively) fused to the SV40 nuclear localizing signal (NLS). This revealed the immature xylem vesselspecific expression of these promoters in the roots (Supplementary Fig. S2A-C). Several putative transcription factors were also included in these gene sets. In particular, Set 3 included 16 genes that encoded transcription factors such as four NAC-domain proteins, five zinc finger proteins, and three Myb proteins (Supplementary Table S1). These might control the gene expression for xylem vessel formation. The four Arabidopsis NACdomain proteins in Set 3 showed a significant similarity to the zinnia NAC-domain protein encoded by an expressed sequence tag, Z567, which showed up-regulated expression during the zinnia in vitro xylem vessel element formation (Demura et al. 2002). Several reports also indicated that NAC-domain proteins play pivotal roles, such as during morphogenesis and in hormone signaling in plants (Aida et al. 1997; Sablowski and Meyerowitz 1998; Xie et al. 2000; Duval et al. 2002; Tran et al. 2004). For these reasons, we focused on the NACdomain-encoding genes for further analysis.

By searching the Arabidopsis genome for genes with similarity to the full-length sequence of Z567, we identified three additional NAC-domain genes that belong to the same subfamily. We designated these seven genesAt2g18060, At4g36160, At5g66300, Atlg12260, Atlg62700, At5g62380, and At1g71930-as VASCULAR-RELATED NAC-DOMAIN PROTEIN 1 (VND1) to VND7, respectively (Fig. 2A; Supplementary Fig. S3). Microarray analysis revealed that $V N D 1, V N D 2$, and VND6 as well as $V N D 3, V N D 4, V N D 5$, and $V N D 7$ classified into Set 3, were up-regulated during in vitro xylem vessel element formation (Fig. 2B; Supplementary Table S1). This suggested the vascular formation-preferential expression of this gene family. The vascular cell-specific expression of all the $V N D$ genes was confirmed by the promoter analysis with the YFP-NLS and GUS as reporters (Fig. $2 \mathrm{C}$; Supplementary Fig. S4). VND1p to VND3p::YFP$N L S$ were expressed preferentially in procambial cells adjacent to root meristem. Expression of $V N D 4 p$ to $V N D 7 p:: Y F P-N L S$ was observed predominantly in immature xylem vessels without obvious secondary wall thickenings. In particular, expression of VND6p::YFP$N L S$ was restricted to the central metaxylem vessels in a middle position of the root (Fig. 2C; Supplementary Fig. S4A-C), whereas that of VND7p::YFP-NLS was detected in the immature protoxylem vessels around the position just above the root meristem (Fig. 2C; Supplementary Fig. S4D). In shoots, no obvious expression of VND1p, $V N D 4 p$, and VND6p::GUS was found (data not shown), but the expression of the others was observed preferentially in vascular cells (Supplementary Fig. S4E-H). An alignment of the VND proteins, the Z567 protein, and several other Arabidopsis NAC-domain proteins showed that the putative DNA-binding NAC-domain, which comprised five subdomains, I to V, was highly conserved among NAC-domain proteins (Supplementary Fig. S3). The VND and Z567 proteins specifically contained two novel conserved domains in the C-terminal region, which might be associated with transcription activation (Supplementary Fig. S3; Duval et al. 2002).

To define the function of VND proteins in vascular development, we expressed the VND genes ectopically under the control of the cauliflower mosaic virus $35 \mathrm{~S}$ promoter (35S). None of the $35 S::$ VND1 to VND5 transgenic seedlings showed obvious morphological changes (data not shown). In contrast, we found transdifferentiation of various types of cells into xylem vessel elements, without changing cell shapes, in the hypocotyls and roots of the $35 S:: V N D 6$ and VND7 transgenic seedlings (Fig. 3A-C). The transdifferentiation into xylem vessel elements occurred mainly in the epidermis of the hypocotyls (Fig. 3A) and in the xylem parenchyma cells, some pericycle, endodermal, and cortex cells of the developed roots (Fig. 3B). Surprisingly, in the roots, the morphology of the transdifferentiated xylem vessel elements in $35 S:: V N D 6$ and $35 S:: V N D 7$ plants was clearly different. Whereas VND6 induced xylem vessel elements with reticulate and pitted thickenings of the secondary wall that were similar to metaxylem vessels, VND7 induced xylem vessel elements with annular and spiral thickenings that were similar to protoxylem vessels (Fig. 3B; Supplementary Fig. S1B). The transdifferentiation into xylem vessel elements also occurred in several cell types of adult $35 S:: V N D 6$ and VND7 plants. These included the epidermal cells such as guard cells of rosette leaves (Fig. 3C).

A promoter analysis of the three immature xylem vessel-specific genes, AtXyn3, IRX3, and the laccase gene (At2g38080), indicated their ectopic expression in 35S::VND7 plants (Supplementary Fig. S2D-F). This suggested that at least a part of immature xylem vesselspecific genes were regulated by VND7. To examine the generality of the VND6 and VND7 function in plants, VND6 and VND7 were overexpressed in poplar plants under the control of $35 \mathrm{~S}$. This resulted in the transdifferentiation of mesophyll or epidermal cells in the leaves 

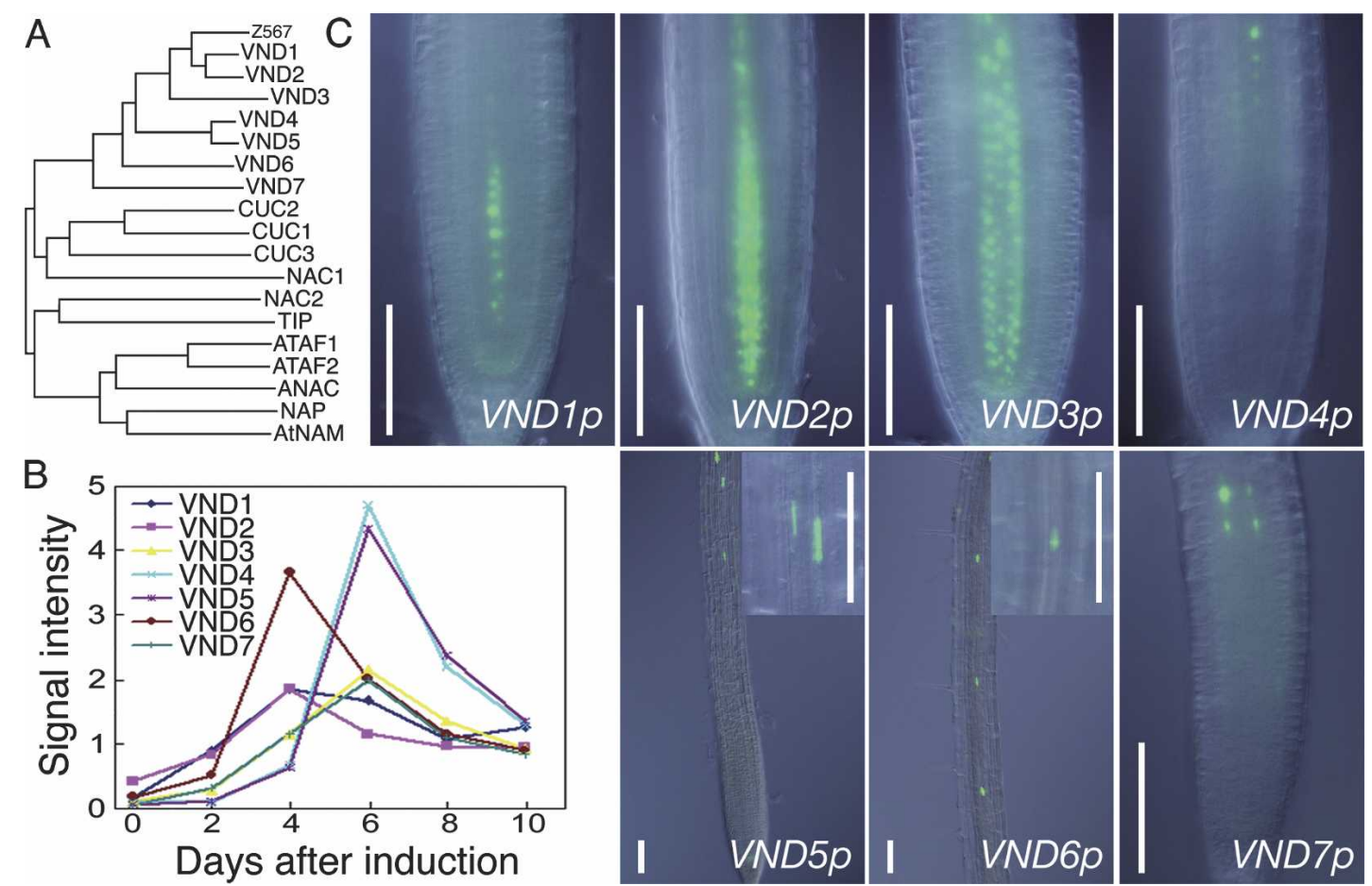

Figure 2. Characterization of the VND genes. (A) Neighbor-joining tree of selected NAC-domain proteins of zinnia and Arabidopsis. Amino acid sequences were aligned by using the MAFFT program. (B) Expression patterns of VND1 to VND7 during in vitro xylem vessel element formation revealed by microarray analysis. (C) Expression of $V N D p:: Y F P-N L S$ in Arabidopsis roots. Images of differential interference contrast (DIC) and YFP fluorescence were merged. Bars, $100 \mu \mathrm{m}$.

of 35S:: VND6 and VND7 poplar plants into metaxylemand protoxylem-like vessel elements, respectively (Fig. 3D).

To examine the subcellular location of the VND6 and VND7 proteins, VND6 and VND7 fused to YFP were overexpressed by the $35 \mathrm{~S}$ promoter in Arabidopsis. VND6-YFP and VND7-YFP fluorescence was located in the nucleus of transgenic plants, in which transdifferentiation to xylem vessel elements occurred similarly to that in $35 S:: V N D 6$ and VND7 plants (Supplementary Fig. S5). This result suggested that the VND6 and VND7 function as nuclear transcription regulators.

To investigate the intrinsic VND6 and VND7 function further, we analyzed loss-of-function phenotypes of VND6 and VND7. Transfer-DNA (T-DNA) insertion mutants of VND6 (GABI_567F08) and VND7 (SALK_063329, SALK_112924 and SALK_115812), and transgenic plants with the expression of antisense RNA or RNAi for VND6 and VND7 did not show any detectable defects in morphology (data not shown). This lack of loss-of-function phenotype of VND6 and VND7 may be presumably due to gene redundancy. However, transgenic seedlings with overexpressed VND6 and VND7 proteins fused to the SRDX strong repression domain driven by $35 S$ (VND6-SRDX and VND7-SRDX) displayed defects in growth and vessel formation in the roots (Fig. 4; Hiratsu et al. 2003). Although root growth in VND6-SRDX seedlings was inhibited slightly, that in $V N D 7-S R D X$ seedlings was inhibited strongly (Fig. 4B,C; Supplementary Fig. S6). Overexpression of VND6SRDX repressed central metaxylem vessel formation, while protoxylem vessel formation was normal (Fig. 4E; Supplementary Fig. S6). In contrast, overexpression of VND7-SRDX repressed protoxylem vessel formation without affecting metaxylem vessel formation (Fig. 4F, Supplementary Fig. S6). A control experiment revealed that such defects were not observed in transgenic seedlings with overexpression of SRDX fused with another Arabidopsis NAC-domain protein, NAC1 (Xie et al. 2000; data not shown).

Auxin, cytokinin, and brassinosteroids play pivotal roles in xylem vessel formation (Fukuda 2004). Therefore, we investigated the effects of phytohormones on expression levels of VND6 and VND7 by culturing hypocotyls of wild-type and transgenic VND6p and VND 7p::GUS Arabidopsis seedlings in the presence of these phytohormones for $5 \mathrm{~d}$ (Fig. 5; Supplementary Fig. S7). The presence of both auxin and cytokinin was required for significant expression of both VND6 and VND7 (Fig. 5). In the combination, VND6p::GUS was expressed strongly in newly proliferating cells derived presumably from pericycle, while VND7p::GUS was expressed only in some cells just beside xylem vessels (Supplementary Fig. S7). The highest expression of VND6 and VND7 was detected in the presence of all three hormones (Fig. 5). Under this condition, new cell proliferation was prevented in the cultured hypocotyls, in which expression of VND7 extended along by the vessel strands and VND6 was expressed in limited vascular cells at the edge of the hypocotyls (Supplementary Fig. S7). These results indicated that VND6 and VND7 function downstream of the signal transduction pathway of these phytohormones.

It is well known that cell fate in vertebrates is sometimes regulated by master regulator genes such as the MyoD family, which has a remarkable capacity to direct the skeletal muscle cell-specific transcriptional program 


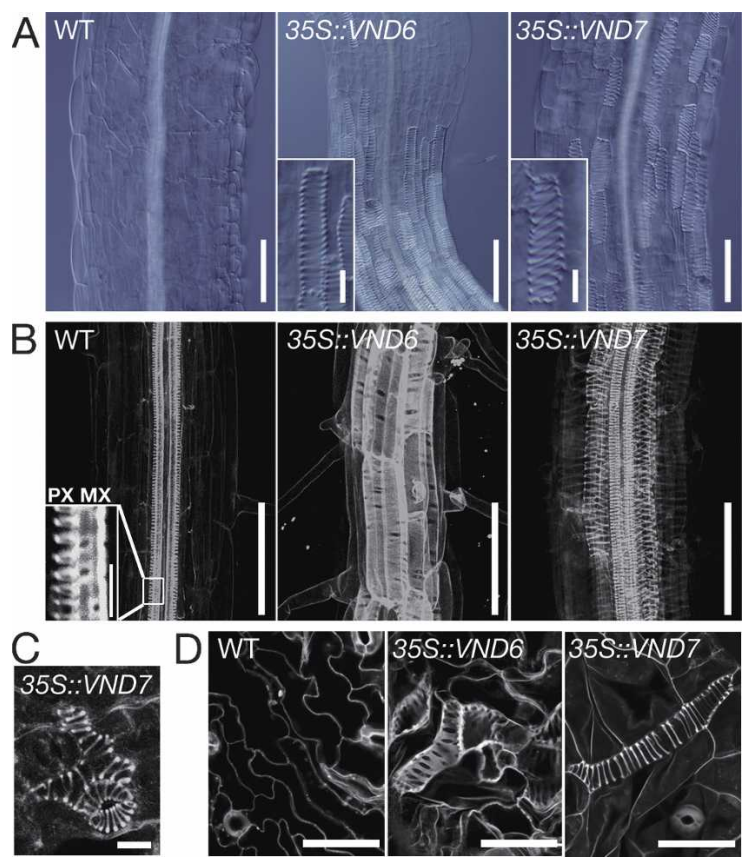

Figure 3. Overexpression phenotypes of VND6 and VND7. (A) Longitudinal DIC images of Arabidopsis hypocotyls. $(B)$ Longitudinal confocal laser scanning microscope (CLSM) images of Arabidopsis roots. $(C)$ CLSM image of epidermis of Arabidopsis rosette leaf. $(D)$ CLSM images of epidermis in the poplar leaves. (PX) Protoxylem vessel; (MX) metaxylem vessel. Bars: $A, B, 100 \mu \mathrm{m}$; insets in $A, 20$ $\mu \mathrm{m} ; C$, insets in $B, 10 \mu \mathrm{m} ; D, 50 \mu \mathrm{m}$.

(Pownall et al. 2002). In contrast, only little is known about the master genes directing cell fate in plants, except for GL2 and PLT for differentiation of plant hair cells and the quiescent center as a stem cell niche in root, respectively (Schiefelbein 2003; Aida et al. 2004). Data presented here indicate that VND6 and VND7 independently have the ability to regulate cell fate of metaxylem and protoxylem vessel elements, respectively, probably through controlling the expression of different target genes. Identification of target genes is one of the most important next steps toward the further understanding of the role of VND6 and VND7. The transdifferentiation into vessel elements by overexpression of VND6 and VND7 occurred not only in vascular cells such as those in the stele of the roots, but also in nonvascular cells such as epidermal cells including guard cells without intervening cell division and changing cell shape in Arabidopsis, which strengthened the idea that VND6 and VND7 are master regulators for vessel cell fate.

The VND genes form a subfamily that belongs to a large family of the NAC-domain transcription factor genes. Other members of the NAC-domain-containing gene family, CUP-SHAPED COTYLEDON 1 (CUC1), $C U C 2$, and $C U C 3$, are partly functionally redundant in shoot apical meristem formation (Vroemen et al. 2003), and both the dominant repression of CUC1 or CUC2 with the SRDX repression domain and the cuc1/cuc2 double mutations cause the loss of the shoot apical meristem (Hiratsu et al. 2003). Expression of the VND genes partially overlaps in some vascular tissues, suggesting partially redundant functions. Indeed, similarly to CUC genes, loss-of-function mutations, T-DNA insertions, and antisense or RNAi expression of the VND6 and $V N D 7$ genes did not show any detectable defects in morphology, while the dominant repression of VND6 and VND7 repressed metaxylem and protoxylem formation, respectively. Further analysis of the redundant functions of VND members is necessary to understand the hierarchical gene regulation responsible for the development of various types of vascular cells, as well as for xylem vessel element formation.

Overexpression of these genes in poplar leaves can also induce transdifferentiation of mesophyll and epidermal cells into metaxylem- and protoxylem-like vessel elements with different secondary walls. This result suggests that the hierarchical genetic control of vessel formation might be conserved evolutionarily. Therefore, functional analyses of $V N D$ genes may provide basic knowledge for improvements in wood biomass production.

\section{Materials and methods}

\section{Plant materials}

Fifteen milliliters of Arabidopsis Col-0 suspension cells (Mathur et al. 1998b) were transferred to $35 \mathrm{~mL}$ of a freshly modified Murashige and Skoog (MS) medium supplemented with $1 \mu \mathrm{g} / \mathrm{mL}$ 2,4-dichlorphenoxyace-



Figure 4. Dominant repression phenotypes of VND6 and VND7 in Arabidopsis. $(A-C)$ Fourteen-day-old seedlings. $(D-F)$ Longitudinal DIC images of vascular bundles in a middle region of the 9-d-old roots. White arrows indicate protoxylem vessels. Black and red arrowheads indicate primary and central metaxylem vessels, respectively. $(A, D)$ Wild type. $(B, E)$ VND6-SRDX. (C,F) VND7-SRDX. Bars: $A-C, 10 \mathrm{~mm} ; D-F, 20 \mu \mathrm{m}$. 




Figure 5. Effects of phytohormones on expression levels of VND6 and VND7 in cultured hypocotyls. (F) Hormone free; (K) $50 \mathrm{ng} / \mathrm{mL}$ kinetin; (D) $500 \mathrm{ng} / \mathrm{mL}$ 2,4-dichlorphenoxyacetic acid; (BL) $1 \mu \mathrm{M}$ brassinolide. Relative expression levels between VND6 and $U B Q$, and $V N D 7$ and $U B Q$ are shown as compared with the hormone-free condition. Results are means $\pm \mathrm{SD}(n=3)$.

tic acid and $3 \%$ sucrose every $7 \mathrm{~d}$, and subcultured on a rotary shaker at $120 \mathrm{rpm}$ in the dark at $22^{\circ} \mathrm{C}$. For xylem vessel element induction, a 7.5-mL aliquot of 7-d-old subcultured cells was transferred into $42.5 \mathrm{~mL}$ of fresh medium that included $1 \mu \mathrm{M}$ brassinolide and $10 \mathrm{mM} \mathrm{H}_{3} \mathrm{BO}_{3}$, and cultured as described above. The frequency of xylem vessel element formation was calculated as the proportion of xylem vessel elements to the number of living cells and the vessel elements. Arabidopsis seeds were sterilized by $70 \%$ ethanol and PPM (Plant Biotechnology), and then placed on germination medium (GM) containing MS medium, $1 \%$ sucrose, $0.05 \%$ MES- $\mathrm{KOH}$ (pH 5.8), B5 vitamins, and $0.3 \%$ phytagel (Sigma). They were treated for $4 \mathrm{~d}$ at $4^{\circ} \mathrm{C}$, and then incubated in growth chamber under continuous illumination at $22^{\circ} \mathrm{C}$. To investigate phytohormone effects on the expression levels of VND6 and VND7, hypocotyls of 5-d-old Arabidopsis Col-0 seedlings grown on GM in dimly lit conditions were excised and incubated on modified MS media supplemented with $2 \%$ glucose and various combinations of phytohormones for $5 \mathrm{~d}$ in the dark at $22^{\circ} \mathrm{C}$. Transformation and regeneration of the poplar hybrid aspen (Populus tremula L. $\times$ Populus tremuloides Michx.) were carried out as described previously (Nilsson et al. 1992).

\section{RNA extraction}

Two independent samples were pooled for microarray and RT-PCR. Total RNA was prepared as described previously (Nishitani et al. 2001), and further purified by using the RNeasy Mini Kit (QIAGEN).

Microarray analysis

Microarray experiment was performed by using ATH1 GeneChips (Affymetrix) according to the manufacturer's instructions as described in Supplemental Materials. The complete data set is available on the TAIR Web site (http://arabidopsis.org).

Plasmid construction and plant transformation

To obtain a full-length cDNA of zinnia Z567 (GenBank accession no. AB217775), a rapid amplification of cDNA ends (RACE)-PCR was performed with the SMART RACE cDNA amplification kit (Clontech). For the promoter analysis, we generated pBGGUS, pBGYN, and pBGCN binary vectors in which the GATEWAY cassette (Invitrogen) was fused to the 5'-ends of GUS, the YFP-NLS, and CFP-NLS (Clontech) fragments on pSMAB704, respectively. For overexpression and antisense RNA expression, we generated binary vectors containing $35 \mathrm{~S}$ with the GATEWAY cassette in the sense (pH35GS) and antisense (pH35GA) orientation on pSMAH621, respectively. For YFP-fusion protein expression and SRDXfusion protein expression, we generated binary vectors containing $35 \mathrm{~S}$ with the sense GATEWAY cassette followed by YFP (pH35GY) and the SRDX strong repression domain (pH35GEAR) on pSMAH621, respectively. Promoter fragments and cDNAs of Arabidopsis genes were amplified from genomic DNA and cDNA pools of the Col-0 ecotype by PCR with gene-specific primer sets, respectively (Supplementary Table S2). They were then subcloned into a pDONR or $\mathrm{pENTR/D/TOPO} \mathrm{vector}$ (Invitrogen), and then integrated into the GATEWAY binary vectors using LR clonase (Invitrogen). The resulting plasmids were electroporated into Agrobacterium strain GV3101::pMP90, which was used to transform Arabidopsis ecotype Col-0 with the floral dip method. Multiple transgenic lines were obtained by selection on GM supplemented with $10 \mu \mathrm{g} / \mathrm{mL}$ bialaphos or $20 \mu \mathrm{g} / \mathrm{mL}$ hygromycin.

\section{Histology}

For observation of the promoter::reporter lines, 4-, 5-, or 7-d-old seedlings were used. A GUS staining method was previously described (Pyo et al. 2004). The 7-and 9-d-old seedlings of the overexpression lines and the dominant repression lines, respectively, were fixed in $90 \%(\mathrm{v} / \mathrm{v})$ acetone for $2 \mathrm{~h}$ to $2 \mathrm{~d}$, rinsed with $100 \mathrm{mM}$ phosphate buffer ( $\mathrm{pH} 7.2)$ at least three times, and then cleared in a clearing solution $(8 \mathrm{~g}$ of chloral hydrate, $1 \mathrm{~mL}$ of glycerol, and $2 \mathrm{~mL}$ of water). Fluorescent and DIC images were observed under a microscope (BX51; Olympus) and photographed with a digital DP70 camera (Olympus). CLSM images of Arabidopsis and poplar stained by safranin-O (Kitin et al. 2000) were detected under a confocal laser scanning microscope (FV-1000; Olympus). Images were processed with Adobe Photoshop CS.

\section{$R T-P C R$}

From total RNA after DNase treatment, cDNAs were synthesized by SuperScriptII reverse transcriptase (Invitrogen) with oligo(dT) primers. Semiquantitative RT-PCR was undertaken by using QuantiTect SYBR green PCR kit (QIAGEN) with a LightCycler (Roche) according to the manufacturers' instructions. Gene-specific primer sets for VND6, VND7, and ubiquitin (At5g57860) are described in Supplementary Table S2.

\section{Acknowledgments}

We thank A. Ihara, G. Tashiro, and M. Araki for technical assistance; H. Ichikawa for providing binary vectors, pSMAB704 and pSMAH621; C. Koncz for providing Agrobacterium strain GV3101::pMP90; C. Koncz and M. Umeda for providing Arabidopsis Col-0 cell suspension; B. Sundberg for providing the poplar hybrid aspen; SIGnAL, ABRC, and GABI-Kat for providing T-DNA insertion lines; and M. Ohme-Takagi for useful advice on the dominant repression method. This work was supported in part by Grants-in-Aid from the Ministry of Education, Science, Sports and Culture of Japan (no. 14036205 to H.F.), from the Mitsubishi Foundation to H.F., and from the Japan Society for the Promotion of Science (no. 15770043 to T.D. and no. 15370018 to H.F.).

\section{References}

Aida, M., Ishida, T., Fukaki, H., Fujisawa, H., and Tasaka, M. 1997. Genes involved in organ separation in Arabidopsis: An analysis of the cup-shaped cotyledon mutant. Plant Cell 9: 841-857.

Aida, M., Beis, D., Heidstra, R., Willemsen, V., Blilou, I., Galinha, C., Nussaume, L., Noh, Y.S., Amasino, R., and Scheres, B. 2004. The PLETHORA genes mediate patterning of the Arabidopsis root stem cell niche. Cell 119: 109-120.

Bonke, M., Thitamadee, S., Mähönen, A.P., Hauser, M.T., and Helariutta, Y. 2003. APL regulates vascular tissue identity in Arabidopsis. Nature 426: 181-186.

Caño-Delgado, A., Yin, Y., Yu, C., Vafeados, D., Mora-Garc, S., Cheng, J.C., Nam, K.H., Li, J., and Chory, J. 2004. BRL1 and BRL3 are novel brassinosteroid receptors that function in vascular differentiation in Arabidopsis. Development 131: 5341-5351.

Choe, S., Dilkes, B.P., Fujioka, S., Takatsuto, S., Sakurai, A., and Feldmann, K.A. 1998. The DWF4 gene of Arabidopsis encodes a cytochrome P450 that mediates multiple $22 \alpha$-hydroxylation steps in brassinosteroid biosynthesis. Plant Cell 10: 231-243.

Demura, T., Tashiro, G., Horiguchi, G., Kishimoto, N., Kubo, M., Matsuoka, N., Minami, A., Nagata-Hiwatashi, M., Nakamura, K., Okamura, Y., et al. 2002. Visualization by comprehensive microarray analysis of gene expression programs during transdifferentiation of mesophyll cells into xylem cells. Proc. Natl. Acad. Sci. 99: 1579415799.

Duval, M., Hsieh, T.F., Kim, S.Y., and Thomas, T.L. 2002. Molecular characterization of AtNAM: A member of the Arabidopsis NAC domain superfamily. Plant Mol. Biol. 50: 237-248.

Emery, J.F., Floyd, S.K., Alvarez, J., Eshed, Y., Hawker, N.P., Izhaki, A., Baum, S.F., and Bowman, J.L. 2003. Radial patterning of Arabidopsis shoots by class III HD-ZIP and KANADI genes. Curr. Biol. 13: 17681774 . 
Kubo et al.

Esau, K. 1977. Anatomy of seed plants, 2nd ed. Wiley, New York. Fukuda, H. 2004. Signals that control plant vascular cell differentiation. Nat. Rev. Mol. Cell Biol. 5: 379-391.

Gälweiler, L., Guan, C., Müller, A., Wisman, E., Mendgen, K., Yephremov, A., and Palme, K. 1998. Regulation of polar auxin transport by AtPIN1 in Arabidopsis vascular tissue. Science 282: 2226-2230.

Hiratsu, K., Matsui, K., Koyama, T., and Ohme-Takagi, M. 2003. Dominant repression of target genes by chimeric repressors that include the EAR motif, a repression domain, in Arabidopsis. Plant J. 34: 733-739.

Kitin, P., Funada, R., Sano, Y., and Ohtani, J. 2000. Analysis by confocal microscopy of the structure of cambium in the hardwood Kalopanax pictus. Ann. Botany 86: 1109-1117.

Mathur, J., Molnár, G., Fujioka, S., Takatsuto, S., Sakurai, A., Yokota, T., Adam, G., Voigt, B., Nagy, F., Maas, C., et al. 1998a. Transcription of the Arabidopsis CPD gene, encoding a steroidogenic cytochrome P450, is negatively controlled by brassinosteroids. Plant J. 14: 593602.

Mathur, J., Szabados, L., Schaefer, S., Grunenberg, B., Lossow, A., JonasStraube, E., Schell, J., Koncz, C., and Koncz-Kálmán, Z. 1998b. Gene identification with sequenced T-DNA tags generated by transformation of Arabidopsis cell suspension. Plant J. 13: 707-716.

Motose, H., Sugiyama, M., and Fukuda, H. 2004. A proteoglycan mediates inductive interaction during plant vascular development. Nature 429: 873-878.

Nilsson, O., Alden, T., Sitbon, F., Little, C.H.A., Chalupa, V., Sandberg, G., and Olsson, O. 1992. Spatial pattern of cauliflower mosaic virus $35 \mathrm{~S}$ promoter luciferase expression in transgenic hybrid aspen trees monitored by enzymatic assay and non-destructive imaging. Transgenic Res. 1: 209-220.

Nishitani, C., Demura, T., and Fukuda, H. 2001. Primary phloem-specific expression of a Zinnia elegans homeobox gene. Plant Cell Physiol. 42: 1210-1218.

Oh, S., Park, S., and Han, K.H. 2003. Transcriptional regulation of secondary growth in Arabidopsis thaliana. J. Exp. Bot. 54: 2709-2722.

Ohashi-Ito, K. and Fukuda, H. 2003. HD-zip III homeobox genes that include a novel member, ZeHB-13 (Zinnia)/ATHB-15 (Arabidopsis), are involved in procambium and xylem cell differentiation. Plant Cell Physiol. 44: 1350-1358.

Pownall, M.E., Gustafsson, M.K., and Emerson, C.P. 2002. Myogenic regulatory factors and the specification of muscle progenitors in vertebrate embryos. Annu. Rev. Cell. Dev. Biol. 18: 747-783.

Przemeck, G.K., Mattsson, J., Hardtke, C.S., Sung, Z.R., and Berleth, T. 1996. Studies on the role of the Arabidopsis gene MONOPTEROS in vascular development and plant cell axialization. Planta 200: 229237.

Pyo, H., Demura, T., and Fukuda, H. 2004. Spatial and temporal tracing of vessel differentiation in young Arabidopsis seedlings by the expression of an immature tracheary element-specific promoter. Plant Cell Physiol. 45: 1529-1536.

Raven, P.H., Evert, R.F., and Eichhorn, S.E. 1999. Biology of plants, 6th ed. Freeman Co., New York.

Sablowski, R.W. and Meyerowitz, E.M. 1998. A homolog of NO APICAL MERISTEM is an immediate target of the floral homeotic genes APETALA3/PISTILLATA. Cell 92: 93-103.

Sawa, S., Demura, T., Horiguchi, G., Kubo, M., and Fukuda, H. 2005. The $A T E$ genes are responsible for repression of transdifferentiation into xylem cells in Arabidopsis. Plant Physiol. 137: 141-148.

Schiefelbein, J. 2003. Cell-fate specification in the epidermis: A common patterning mechanism in the root and shoot. Curr. Opin. Plant Biol. 6: 74-78.

Taylor, N.G., Scheible, W.R., Cutler, S., Somerville, C.R., and Turner, S.R. 1999. The irregular xylem3 locus of Arabidopsis encodes a cellulose synthase required for secondary cell wall synthesis. Plant Cell 11: 769-780.

Tran, L.S., Nakashima, K., Sakuma, Y., Simpson, S.D., Fujita, Y., Maruyama, K., Fujita, M., Seki, M., Shinozaki, K., and Yamaguchi-Shinozaki, K. 2004. Isolation and functional analysis of Arabidopsis stress-inducible NAC transcription factors that bind to a droughtresponsive cis-element in the early responsive to dehydration stress 1 promoter. Plant Cell 16: 2481-2498.

Vroemen, C.W., Mordhorst, A.P., Albrecht, C., Kwaaitaal, M.A., and de Vries, S.C. 2003. The CUP-SHAPED COTYLEDON3 gene is required for boundary and shoot meristem formation in Arabidopsis. Plant Cell 15: 1563-1577.

Xie, Q., Frugis, G., Colgan, D., and Chua, N.H. 2000. Arabidopsis NAC1 transduces auxin signal downstream of TIR1 to promote lateral root development. Genes \& Dev. 14: 3024-3036.

Ye, Z.H. 2002. Vascular tissue differentiation and pattern formation in plants. Annu. Rev. Plant Biol. 53: 183-202.

Zhou, A., Wang, H., Walker, J.C., and Li, J. 2004. BRL1, a leucine-rich repeat receptor-like protein kinase, is functionally redundant with BRI1 in regulating Arabidopsis brassinosteroid signaling. Plant J. 40: 399-409. 


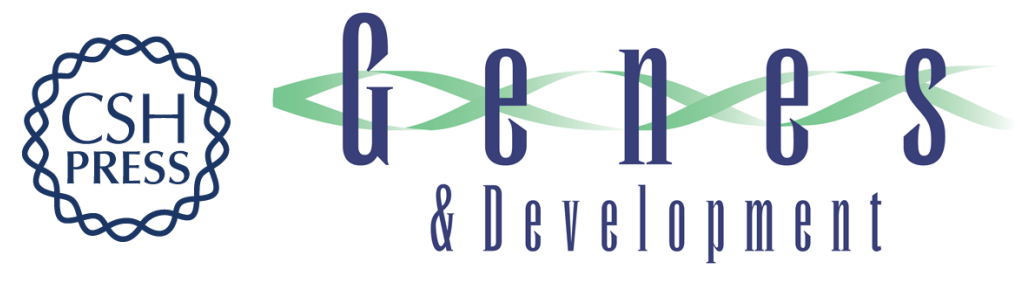

\section{Transcription switches for protoxylem and metaxylem vessel formation}

Minoru Kubo, Makiko Udagawa, Nobuyuki Nishikubo, et al.

Genes Dev. 2005, 19:

Access the most recent version at doi:10.1101/gad.1331305

\section{Supplemental http://genesdev.cshlp.org/content/suppl/2005/08/16/19.16.1855.DC1 Material}

References This article cites 30 articles, 10 of which can be accessed free at: http://genesdev.cshlp.org/content/19/16/1855.full.html\#ref-list-1

\section{License}

Email Alerting

Receive free email alerts when new articles cite this article - sign up in the box at the top Service right corner of the article or click here.



